Check for updates

Cite this: RSC Adv., 2019, 9, 22609

\title{
Occurrence and health risk assessment of volatile organic compounds in the surface water of Poyang Lake in March 2017†
}

\author{
Pan Qin, (DD ${ }^{a b}$ Fengmei Cao, (D) ${ }^{b}$ Shaoyong Lu, ${ }^{\text {ab }}$ Linlin Li, ${ }^{\text {ab }}$ Xiaochun Guo, \\ Bin Zhao, ${ }^{\mathrm{c}}$ Zhengfen $\mathrm{Wan}^{\mathrm{b}}$ and $\mathrm{Bin} \mathrm{Bi}^{\mathrm{b}}$
}

\begin{abstract}
An investigation into the occurrence of volatile organic compounds (VOCs) in the surface water of Poyang Lake was conducted. The determination of 54 different kinds of VOCs was performed with a purge and trap-gas chromatography-mass spectrometry method at 28 sampling points. Twenty-two types of VOCs were detected; methylene chloride had the highest mean concentration of $708.19 \mathrm{ng} \mathrm{L}^{-1}$, followed by 1,2-dichloroethane and chloroform, with mean concentrations of 376.78 and $187.26 \mathrm{ng} \mathrm{L}^{-1}$, respectively. The distribution of VOCs in the areas of Poyang Lake from low to high was as follows: west and south < east and central; the highest $\sum \mathrm{VOC}$ concentration occurred at the sample site of Zhangsihe. The health risks of VOCs in Poyang Lake were also determined by calculating the cancer and non-cancer risk from the two exposure routes of ingestion and dermal adsorption. The results showed that VOCs have no carcinogenicity risk, while only methylene chloride has a certain carcinogenic risk to the human body.
\end{abstract}

Received 1st April 2019

Accepted 6th July 2019

DOI: $10.1039 / c 9 r a 02450 f$

rsc.li/rsc-advances

such as ozone, which may disturb the balance of the

\section{Introduction}

Volatile organic compounds (VOCs) are among the most common environmental pollutants, and their saturated vapor pressures are greater than or equal to $0.01 \mathrm{kPa}$ at $20{ }^{\circ} \mathrm{C} .{ }^{1}$ Their boiling points are generally below $260{ }^{\circ} \mathrm{C}$ at atmospheric pressure $(101.325 \mathrm{kPa}) .{ }^{2}$ VOCs include a wide range of species, such as alkanes (linear alkanes and cycloalkanes), olefins, alkynes, benzene, alcohols, aldehydes, ethers, ketones, acids, esters, and halogenated hydrocarbons. ${ }^{3}$ The main emission sources of voCs come from natural and anthropogenic activities. The former is related to the secondary metabolic reactions of terrestrial vegetation, and the latter is derived from incomplete combustion during human activities, the volatility of lowboiling-point substances and by-products of industrial processes. ${ }^{4,5}$ However, an increasing number of studies have indicated that VOCs have harmful effects on the environment and human health. ${ }^{6-9}$ VOCs can participate in photochemical reactions, thus generating highly oxidized gases,

${ }^{a}$ College of Water Sciences, Beijing Normal University, Beijing 100875, China. E-mail: lushy2000@163.com; Tel: +86-10-84935064

${ }^{b}$ State Environmental Protection Scientific Observation and Research Station for Lake Dongtinghu (SEPSORSLD), National Engineering Laboratory for Lake Pollution Control and Ecological Restoration, State Key Laboratory of Environmental Criteria and Risk Assessment, Research Centre of Lake Environment, Chinese Research Academy of Environmental Sciences, Beijing 100012, China

${ }^{c} Y u x i$ Normal University, Yuxi, Yunan 653100, China

$\dagger$ Electronic supplementary information (ESI) available. See DOI: $10.1039 / \mathrm{c} 9 \mathrm{ra} 02450 \mathrm{f}$ ecosystem. ${ }^{10,11}$ Gałęzowska et al. showed that VOCs contribute to respiratory system disorders. ${ }^{12}$ In addition, some research has noted that VOCs may lead to cancers, malformations and mutations. ${ }^{13}$ The Chinese government is focusing on strengthening the control of emissions of VOCs. There have been approximately 10 national emission standards published, and approximately 20 standards are in progress, which will form a more systematic VOC control standard system. However, these measures mostly involve the atmospheric environment, and VOCs in water are rarely considered. An increasing number of investigations have shown that VOCs exist in water and may give rise to various risks. ${ }^{14,15}$ Accordingly, it is essential to government environmental policymakers to understand the hazards of VOCs in source water, in addition to the current pollution level. However, the study of VOCs in water is still at the initial stage, and the state of knowledge is not sufficient to identify the criteria of greatest concern and provide complete hazard information. These hazardous VOCs in water sources may not only affect the aquatic ecosystem but also cause human health risks when they are present in raw water used for drinking water. Therefore, it is crucial to investigate the occurrence and to develop a health risk assessment of VOCs in lakes and rivers.

Poyang Lake, the largest freshwater lake in China, is located in the northern part of Jiangxi Province and plays an important role in regulating the Yangtze River water level, conserving water sources, improving the local climate and maintaining the ecological balance of the surrounding 
areas. ${ }^{16}$ VOC pollution in Poyang Lake probably poses a substantial threat to the health of humans and ecosystems. ${ }^{17,18}$ Additionally, there has been no research reported on the occurrence and risk assessment of VOCs in Poyang Lake. In this paper, to provide a basis and suggestions for the treatment and management of VOCs in Poyang Lake, the occurrence and distribution characteristics of VOCs were analysed, and a health risk assessment was carried out at the same time. The results will contribute to the knowledge on potential hazards from various VOCs in Poyang Lake in China, and these results will lead to developments in the urgently needed management of contaminant loading and corresponding policies.

\section{Materials and methods}

\subsection{Water sample collection}

Twenty-eight samples of surface water in Poyang Lake were collected based on uniform sampling principles in March 2017. The sampling points are shown in Fig. 1. Northern Dajishan is located in the northern area of Poyang Lake, and the water flows through Xinchixiang, Laoyemiao, Pingfen and Xieshan to the Yangtze River. The southern area is the main body of Poyang Lake, accounting for approximately four-fifths of the total area of the lake. The southernmost, easternmost and westernmost points are Junshanhu, Zhangsihe and Dahuchi, respectively. The Fuhe River merges into Poyang Lake at Jinxihu. The Ganjiang River merges into Poyang Lake at Ganjiangzhuzhi, Ganjiangzhongzhi and Ganjiangnanzhi. Kangshanhe, Raohe and Zhangsihe are the locations where the Kangshan River, Rao River and Zhangsi River join Poyang Lake. The basic parameters of the sampling points are shown in Fig. 2. The $\mathrm{pH}$, dissolved oxygen (DO) and temperature $(T)$ ranges of Poyang Lake are 7.06-8.48, 9.68-13.6 $\mathrm{mg} \mathrm{L}^{-1}$, and 10.2$17.3{ }^{\circ} \mathrm{C}$, respectively. The water in Poyang Lake is neutral to weakly alkaline, with high dissolved oxygen levels and an oxygen-rich state. However, the water temperature in Poyang Lake varies greatly, and the highest water temperature is 7.1 degrees higher than the lowest value. The locations with the highest water temperature are Changhu and Xiyuanxiang, which may be related to frequent human activities near these locations. Many ships are operated in the Xhanghu area, and many people live on the shores of Xiyuanxiang.

The samples were collected using $40 \mathrm{~mL}$ glass bottles that had screw caps with rubber-polytetrafluoroethylene gaskets, ensuring that there was no gap between the sample and the cap. Samples were returned to the laboratory using an insulated box

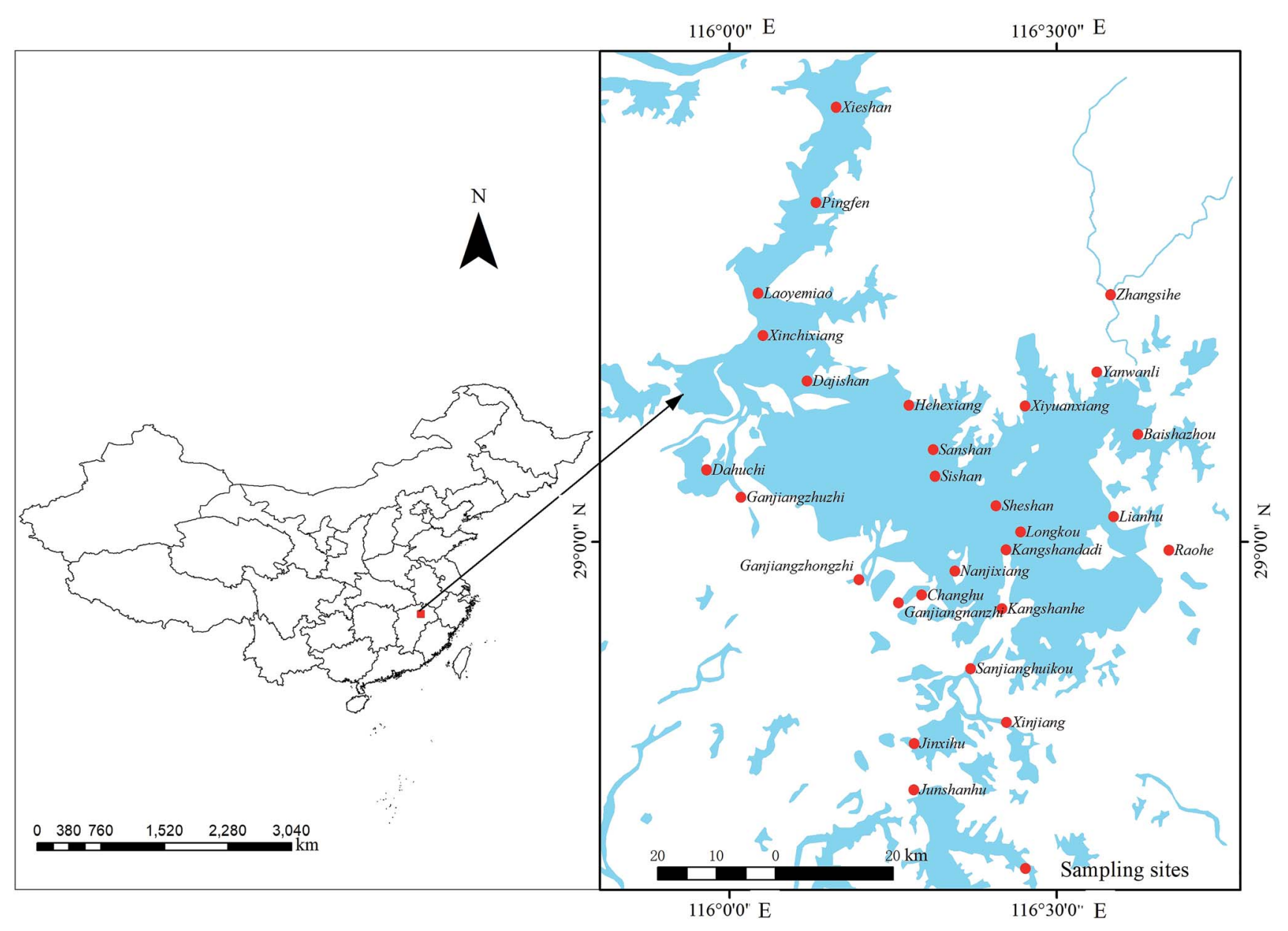

Fig. 1 Sampling points in Poyang Lake. 
and stored in a refrigerator free of organic reagents. Then, the samples were fixed using hydrochloric acid and analysed within 24 hours.

\subsection{Reagents}

A mixed standard solution consisting of 54 compounds, fluorobenzene and 1,2-dichlorobenzene-D4 (USEPA method 524.3) was purchased from Accustandard in the United States. The concentration of the mixed standard solution was $2 \mathrm{~g} \mathrm{~L}^{-1}$. The standard solution for analysis was prepared by dilution with pesticide-grade methanol (purchased from Shanghai Standard Reagent Company).

\subsection{Instrumentation and control conditions}

2.3.1 Purge and trap system. A PT9800 \& Aquatek purge and trap device (Tekmar, USA) was used, and the conditions were set as follows: purge temperature: room temperature or constant temperature; purge tube length: $25 \mathrm{~cm}$; purge flow rate: $40 \mathrm{~mL} \mathrm{~min}^{-1}$; purge time: $11 \mathrm{~min}$; dry blowing time: $1 \mathrm{~min}$; pre-desorption temperature: $180{ }^{\circ} \mathrm{C}$; desorption temperature: $190{ }^{\circ} \mathrm{C}$; desorption time: $2 \mathrm{~min}$; baking temperature: $200{ }^{\circ} \mathrm{C}$; baking time: $6 \mathrm{~min}$.

2.3.2 Gas chromatography-mass spectrometry. An Agilent GC7890 gas chromatograph was used, and the conditions were set as follows: injection method: split injection (split ratio of $30: 1$ ); inlet temperature: $220{ }^{\circ} \mathrm{C}$; carrier gas: high-purity helium (purity $>99.99 \%$ ), flow rate: $1.0 \mathrm{~mL} \mathrm{~min}^{-1}$, constant current mode; temperature program: starting temperature of $35{ }^{\circ} \mathrm{C}$ (hold $2 \mathrm{~min}$ ), ramp at $5{ }^{\circ} \mathrm{C} \min ^{-1}$ to $120{ }^{\circ} \mathrm{C}$, then ramp at $10{ }^{\circ} \mathrm{C} \min ^{-1}$ to $220{ }^{\circ} \mathrm{C}$ (hold $2 \mathrm{~min}$ ).

An Agilent MS5975 mass spectrometer was used, and the conditions were set as follows: ion source temperature: $230{ }^{\circ} \mathrm{C}$; ion source: EI source; scanning method: selective ion scanning; ionization energy: $70 \mathrm{eV}$; scanning range: $m / z$ 35-270 amu.

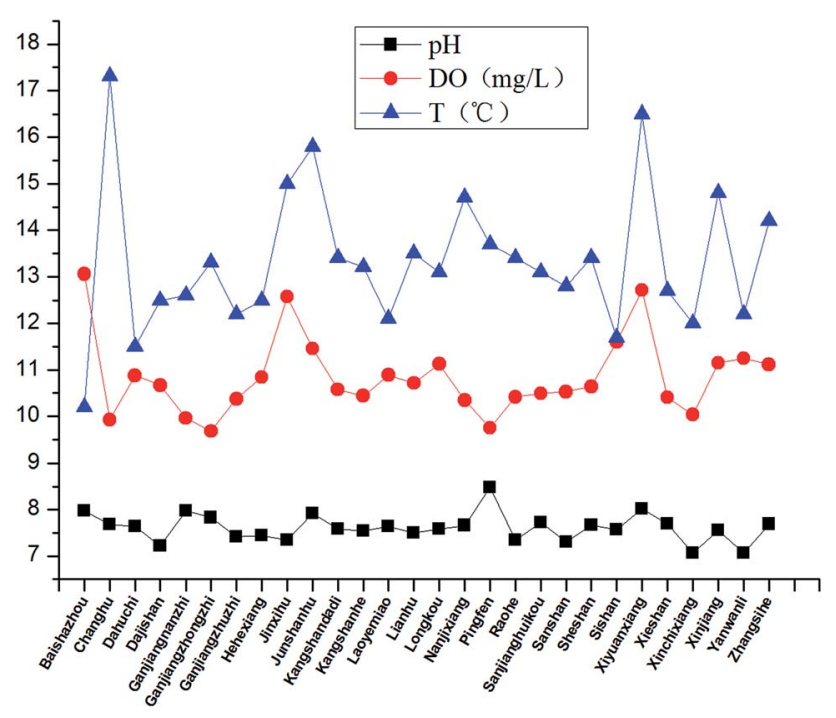

Fig. 2 Basic parameters of sampling points.

\subsection{Sample determination and quality control}

Twenty $\mathrm{mL}$ samples were spiked with $50 \mu \mathrm{L}$ of a $20 \mu \mathrm{g} \mathrm{L} \mathrm{L}^{-1}$ internal standard, analysed according to the instrument control conditions described in Section 1.3, and quantified with the internal standard method. The precision, recovery, limit of detection (LOD), and linear range of the method were consistent with those reported in the literature. ${ }^{19}$ Two parallel analytical samples were collected from each water sample, and the parallel samples were analysed every ten samples. The relative deviation of the parallel sample results was less than $20 \%$. Solvent blanks and procedural blanks showed no detectable amounts of target compounds. The TIC spectra of GC-MS are presented in Fig S1 (in the ESI $\dagger$ ). The LOD and recovery for the detected contaminants are shown in Table S1 (in the ESI $\dagger$ ). The recovery was 82.3$120.5 \%$.

\subsection{Health risk assessment}

There are many methods and models for assessing the health risks of pollutants in water. ${ }^{\mathbf{2 0}-22}$ The health risk assessment model recommended by the USEPA was used to evaluate the health risks of organic pollutants in Poyang Lake. Depending on whether the pollutants are carcinogenic, health risks are classified into carcinogenic and non-carcinogenic. However, carcinogenic pollutants also have non-carcinogenic hazards. Therefore, both carcinogenic and non-carcinogenic risk assessments are carried out for the contaminants.

Risk (cancer risk value) represents the incidence of cancer beyond the normal level of exposure to carcinogenic contaminants and is divided into low-dose exposure risk and high-dose exposure risk. The corresponding formula is as follows:

$$
\begin{gathered}
\text { Risk }=\mathrm{CDI} \times \mathrm{SF}, \text { Risk }<0.01 \\
\text { Risk }=1-\exp (-\mathrm{CDI} \times \mathrm{SF}), \text { Risk } \geq 0.01
\end{gathered}
$$

where CDI $\left(\mathrm{mg}(\mathrm{kg} \mathrm{d})^{-1}\right)$ is the daily average exposure of the human body and SF is the pollutant carcinogenic slope factor $\left(\mathrm{kg} \mathrm{d} \mathrm{mg}{ }^{-1}\right.$ ).

Non-carcinogenic risk is generally measured as a reference dose; i.e., an exposure level higher than the reference dose value may be risky, whereas an exposure level equal to or lower than the reference dose value is within the acceptable risk range. The hazard value (HI) is usually used to represent the reference dose value and is calculated as follows:

$$
\mathrm{HI}=\frac{\mathrm{CDI}}{\mathrm{RfD}}
$$

where $\mathrm{RfD}$ is the non-carcinogenic reference dose of the contaminant $\left(\mathrm{mg}(\mathrm{kg} \mathrm{d})^{-1}\right)$.

The main routes of contaminant exposure to the human body are ingestion and skin contact.

When daily exposure to the human body is through ingestion, CDI is calculated as follows:

$$
\mathrm{CDI}=\frac{\rho \times U \times \mathrm{EF} \times \mathrm{ED}}{\mathrm{BW} \times \mathrm{AT}}
$$


When daily exposure to the human body is through the skin, CDI is calculated as follows:

$$
\begin{gathered}
\mathrm{CDI}=I \times A_{\mathrm{sd}} \times \mathrm{EF} \times \mathrm{FE} \times \mathrm{ED} /(\mathrm{BW} \times \mathrm{AT} \times f) \\
I=2 \times 10^{-3} \times k \times \rho \times \sqrt{6 \times \tau \times T E / \pi}
\end{gathered}
$$

where: $I$ is the amount of contaminant adsorbed by the skin for each exposure event, $\mathrm{mg} \mathrm{cm}{ }^{2} ; A_{\mathrm{sd}}$ is the body surface area, $\mathrm{cm}^{2}$; $\mathrm{EF}$ is the human exposure frequency, $\mathrm{d} \mathrm{a}^{-1} ; \mathrm{FE}$ is the exposure event frequency, times per d; ED is the human exposure delay, a; BW is the average body weight, kg; AT is the average exposure time for the human body, $\mathrm{d} ; f$ is the intestinal adsorption ratio; $k$ is the skin parameter, $\mathrm{cm} \mathrm{h}^{-1} ; \rho$ is the mass concentration of pollutant, $\mathrm{mg} \mathrm{L}^{-1} ; U$ is the daily average ingestion, $\mathrm{L} \mathrm{d}^{-1} ; \tau$ is the delay time, $h$; and TE is the exposure event time, $h$.

According to the literature, ${ }^{23}$ the values of the above formula parameters are as follows: human exposure frequency (EF): 365 $\mathrm{d} \mathrm{a}^{-1}$; exposure event frequency (FE): 0.3 times per $\mathrm{d}$; carcinogenic and non-carcinogenic exposure delay (ED): 70 a and 30 a, respectively; mean body weight (BW): $60 \mathrm{~kg}$; average exposure time to carcinogens and non-carcinogens: $25550 \mathrm{~d}$ and $10950 \mathrm{~d}$, respectively; intestinal adsorption ratio $(f): 1$; skin adsorption parameter $(k): 0.001 \mathrm{~cm} \mathrm{~h}^{-1}$; daily ingestion $(U): 2 \mathrm{~L} \mathrm{~d}^{-1}$; and exposure event time (TE) and delay time: $0.4 \mathrm{~h}$ and $1 \mathrm{~h}$, respectively.

The carcinogenic slope factor (SF) and the reference dose (RfD) of the contaminants used in the calculation were obtained from the USEPA database (https://www.epa.gov/sites/production/files/ 201603/documents/summary_of_inputs_final_revised_3.24.16.pdf) and the literature; ${ }^{24}$ the specific values are listed in Table S2 (in the $\mathrm{ESI} \dagger$ ).

\section{Results and discussion}

\subsection{Occurrence}

The detection results for the 28 samples are shown in Table 1. Twenty-two VOC contaminants were detected, with a concentration range from ND (not detected) to $2809.94 \mathrm{ng} \mathrm{\textrm {L } ^ { - 1 }}$. The concentrations of VOCs detected were lower than the values in both GB3838-2002 ("Standard of Surface Water Quality") and GB5749-2006 ("Standard of Living Drinking Water Sanitation") of China. The frequencies of detection (FODs) of the 22 kinds of VOCs were different. Among them, methylene chloride, chloroform, benzene, 1,2-dichloroethane and toluene were detected at each point. The FODs of ethylbenzene, trans-1,2-dichloroethylene and 1,2-dichloropropane were $89.3 \%, 82.1 \%$ and $82.1 \%$, respectively. The lowest FODs were those of tetrachloroethylene and 1,2-dichlorobenzene, which were only detected at the sampling points of Xieshan and Dahuchi. The FODs of other pollutants ranged from $7.1 \%$ to $78.6 \%$.

Methylene chloride had the highest mean concentration among the 22 kinds of VOCs, which was $708.19 \mathrm{ng} \mathrm{L}^{-1}$, followed by 1,2-dichloroethane and chloroform, with mean concentrations of 376.78 and $187.26 \mathrm{ng} \mathrm{L}^{-1}$, respectively. In addition, the highest concentration of methylene chloride was

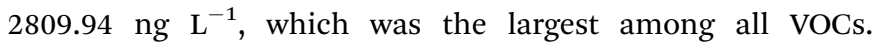

Methylene chloride is mainly used in film production and medicine in China. ${ }^{25}$ 1,2-Dichloroethane is mainly used in the production of tetrachloroethylene and vinyl chloride and is also used as a solvent for lipids, rubber and paint; this compound is one of the 58 priority control pollutants in the water environment in China. ${ }^{26}$ Chloroform may also be derived from chlorine disinfection by-products from drinking water treatment processes. ${ }^{27}$ According to the literature,${ }^{28}$ the industrial development plan around Poyang Lake includes the construction of petrochemical and pharmaceutical industries, which may increase the emissions of VOCs in Poyang Lake. Poyang Lake is the most important water transportation hub in Jiangxi Province. It is very likely that accidents such as leakage will occur during the transportation of chemical products, causing VOCs to enter Poyang Lake. Furthermore, according to the literature, ${ }^{29}$ toluene might be the most ubiquitous common VOC pollutant in Chinese water bodies. This is consistent with the 100\% FOD of toluene in Poyang Lake. It is worth noting that although the mean concentration of benzene was only $27.13 \mathrm{ng} \mathrm{\textrm {L } ^ { - 1 }}$, which is well below its LC50, ${ }^{30}$ its FOD was $100 \%$. Therefore, due to the wide distribution of benzene, it is still necessary to consider the health risks caused by long-term exposure.

\subsection{Spatial distribution}

The distribution of VOCs at each sampling point of Poyang Lake is shown in Fig. 3a. There were 3 points at which the total concentration was over $3000 \mathrm{ng} \mathrm{\textrm {L } ^ { - 1 }}$. These points were Hehexiang, Baishazhou and Zhangsihe. Sheshan, Junshanhu and Dahuchi had the lowest total concentration, less than $500 \mathrm{ng} \mathrm{\textrm {L } ^ { - 1 }}$ in all cases. The levels of VOCs in Poyang Lake were lower in the west and south and higher in the east and centre, and the point with the highest concentration was Zhangsihe. As we can see, the concentration of VOCs in the eastern part of the lake was higher than that in the west and south, which indicated that the eastern rivers are the main contributors to VOCs in Poyang Lake. However, the total concentration of VOCs in Dajishan was lower than that at the sampling points in the south, which showed that VOCs were volatilized or degraded in the central part of Poyang Lake.

The VOC composition in Poyang Lake is shown in Fig. $3 \mathrm{~b}$. The substances with the highest percentages among the 22 VOCs were methylene chloride, accounting for up to $44.60 \%$, nearly half; followed by 1,2-dichloroethane and chloroform, accounting for $23.73 \%$ and $11.79 \%$, respectively. A comparison of the FODs of the VOCs shows that contaminants accounting for a large percentage were detected at each point, demonstrating that VOCs are widely distributed in Poyang Lake. Methylene chloride, chloroform, benzene, 1,2-dichloroethane and toluene are the main VOC contaminants in Poyang Lake. Consequently, because methylene chloride has the highest concentration and the highest content in Poyang Lake, the Chinese government should focus on the production of pollution from the film industry in the Poyang Lake basin. ${ }^{31,32}$ Based on this, we mainly focused on the distribution of methylene chloride in Poyang Lake. Fig. 2 clearly shows that methylene chloride was mainly found in Zhangsihe (2809.94 $\mathrm{ng} \mathrm{\textrm {L } ^ { - 1 }}$ ); this 
Table 1 Detection results of VOCs in Poyang Lake ${ }^{a}$

\begin{tabular}{|c|c|c|c|c|}
\hline Contaminants & FOD, \% & $\begin{array}{l}\text { Minimum (ng } \\
\mathrm{L}^{-1} \text { ) }\end{array}$ & $\begin{array}{l}\text { Maximum (ng } \\
\mathrm{L}^{-1} \text { ) }\end{array}$ & $\begin{array}{l}\text { Mean (ng } \\
\mathrm{L}^{-1} \text { ) }\end{array}$ \\
\hline 1,1-Dichloroethylene & 78.6 & ND & 23.81 & 9.13 \\
\hline trans-1,2-Dichloroethylene & 82.1 & ND & 23.78 & 10.27 \\
\hline cis-1,2-Dichloroethylene & 53.6 & ND & 11.28 & 3.33 \\
\hline Chloroform & 100.0 & 11.84 & 1379.83 & 187.26 \\
\hline Trichloroethylene & 17.9 & ND & 7.91 & 6.49 \\
\hline 1,2-Dichloropropane & 82.1 & ND & 111.54 & 30.14 \\
\hline Bromodichloromethane & 57.1 & 11.58 & 91.31 & 31.79 \\
\hline Toluene & 100.0 & 37.51 & 590.23 & 131.99 \\
\hline Tetrachloroethene & 3.6 & 5.98 & 5.98 & 5.98 \\
\hline Dibromochloromethane & 39.3 & ND & 10.71 & 5.62 \\
\hline$o$-Xylene & 53.6 & ND & 129.02 & 31.06 \\
\hline 1,3,5-Trimethylbenzene & 10.7 & ND & 44.11 & 15.80 \\
\hline 1,3-Dichlorobenzene & 7.1 & ND & 3.60 & 2.53 \\
\hline 1,2-Dichlorobenzene & 3.6 & 1.53 & 1.53 & 1.53 \\
\hline Naphthalene & 21.4 & 38.87 & 67.02 & 54.30 \\
\hline
\end{tabular}

value was higher than that $\left(108.86 \mathrm{ng} \mathrm{\textrm {L } ^ { - 1 }}\right)$ in Raohe, that (115.27 $\left.\mathrm{ng} \mathrm{L}^{-1}\right)$ in Kangshanhe, that $\left(78.75 \mathrm{ng} \mathrm{L}^{-1}\right)$ in Junshanhu, and those $\left(97.81,88.01\right.$, and $\left.871.07 \mathrm{ng} \mathrm{L}^{-1}\right)$ in Gangjiang. Methylene chloride originating from Zhangsihe was reduced in Dajishan (293.47 $\mathrm{ng} \mathrm{L}^{-1}$ ) after passing through Baishazhou (2785.29 $\mathrm{ng} \mathrm{L}^{-1}$ ) and Hehexiang (2190.25 $\mathrm{ng} \mathrm{L}^{-1}$ ). This may be because Dajishan is located at the entrance of the southern rivers into the northern area of Poyang Lake, where the water flow is turbulent and methylene chloride is strongly volatilized and degraded. After that, methylene chloride entered the northern part of the lake in Xinchixiang $\left(672.37 \mathrm{ng} \mathrm{L}^{-1}\right)$ and Laoyemiao (1510.1 $\mathrm{ng} \mathrm{L}^{-1}$ ) and was then reduced in Pingfen (222.92 $\mathrm{ng} \mathrm{\textrm {L } ^ { - 1 }}$ ). Finally, methylene chloride flowed into the Yangtze River through Xieshan (506.2 $\mathrm{ng} \mathrm{L}^{-1}$ ).

\subsection{Comparison}

The distributions of VOCs in lakes/rivers in the literature are shown in Table $2{ }^{19,29,33-38}$ Fifty kinds of VOCs were detected by Chen in 5 rivers; 19 kinds of VOCs were detected by Han in 3 provinces; 15 kinds of VOCs were detected by Nikolaou in 10 rivers and 7 lakes in Greece; and 22 kinds of VOCs were detected by Cao in Dongting Lake. The number of VOCs detected in Poyang Lake was 22, which is obviously high.

Compared to other studies, the reported levels of VOCs varied substantially. In Dongting Lake,$^{38}$ the concentrations of detected VOCs varied from 0.012 (1,1-dichloroethane) to $1.06 \mu \mathrm{g} \mathrm{L}^{-1}$ (bromodichloromethane), and the concentrations of methylene chloride were $61.8-106.7 \mathrm{ng} \mathrm{L}^{-1}$. This result is nearly 28 times lower than the concentration of methylene chloride $\left(2809.94 \mathrm{ng} \mathrm{L}^{-1}\right)$ in Poyang Lake. In addition, methylene chloride was not detected in the rivers associated with the Baitabao River ${ }^{36}$ and in the urban rivers of Shandong, Jiangsu and Zhejiang provinces. ${ }^{37}$ The top 10 most frequently detected common VOCs in typical drinking water sources from 5 major river basins in China were 1,2,4trichlorobenzene, toluene, $m$-xylene, $p$-xylene, $o$-xylene, naphthalene, 1,2-dichloropropane, bromochloromethane, ethylbenzene, and 1,2,3-trichlorobenzene, and for these compounds, the FODs were above $27 \%{ }^{29}$ This is consistent with the FODs of toluene $(100 \%)$ and 1,2-dichloropropane (82.1\%) in Poyang Lake. Chloroform has been classified as a probable human carcinogen on the basis of inadequate evidence in humans, but there is sufficient evidence for carcinogenicity in animals; chloroform had 100\% FODs in both Poyang Lake (11.84-1379.83 $\mathrm{ng} \mathrm{L}^{-1}$ ) and Dongting Lake (100.0-278.3 $\mathrm{ng} \mathrm{L}^{-1}$ ). The concentration range of chloroform in Greece was ND-417 $\mathrm{ng} \mathrm{L}^{-1}$ in rivers and ND$174 \mathrm{ng} \mathrm{L}^{-1}$ in lakes ${ }^{34}$ which was lower than that in Poyang Lake.

The lowest concentration range of VOCs in the literature is $\mathrm{ND} \sim 3.90 \mu \mathrm{g} \mathrm{L}^{-1}$, except for the highest concentrations in Haihe River and Dongting Lake. The highest concentration of VOCs in Poyang Lake was $2.81 \mu \mathrm{g} \mathrm{L}^{-1}$, which is lower than the concentrations in other lakes/rivers, except Haihe River and Dongting Lake. The concentrations of VOCs detected in lakes were lower than those in rivers. This conclusion is similar to the results of Kostopoulou et al. ${ }^{34}$ and Cao et al. ${ }^{38}$ The solubility of VOCs in water is affected by turbulence. Stronger turbulence can naturally increase the amount of VOCs dissolved in water. The turbulence in rivers is stronger 


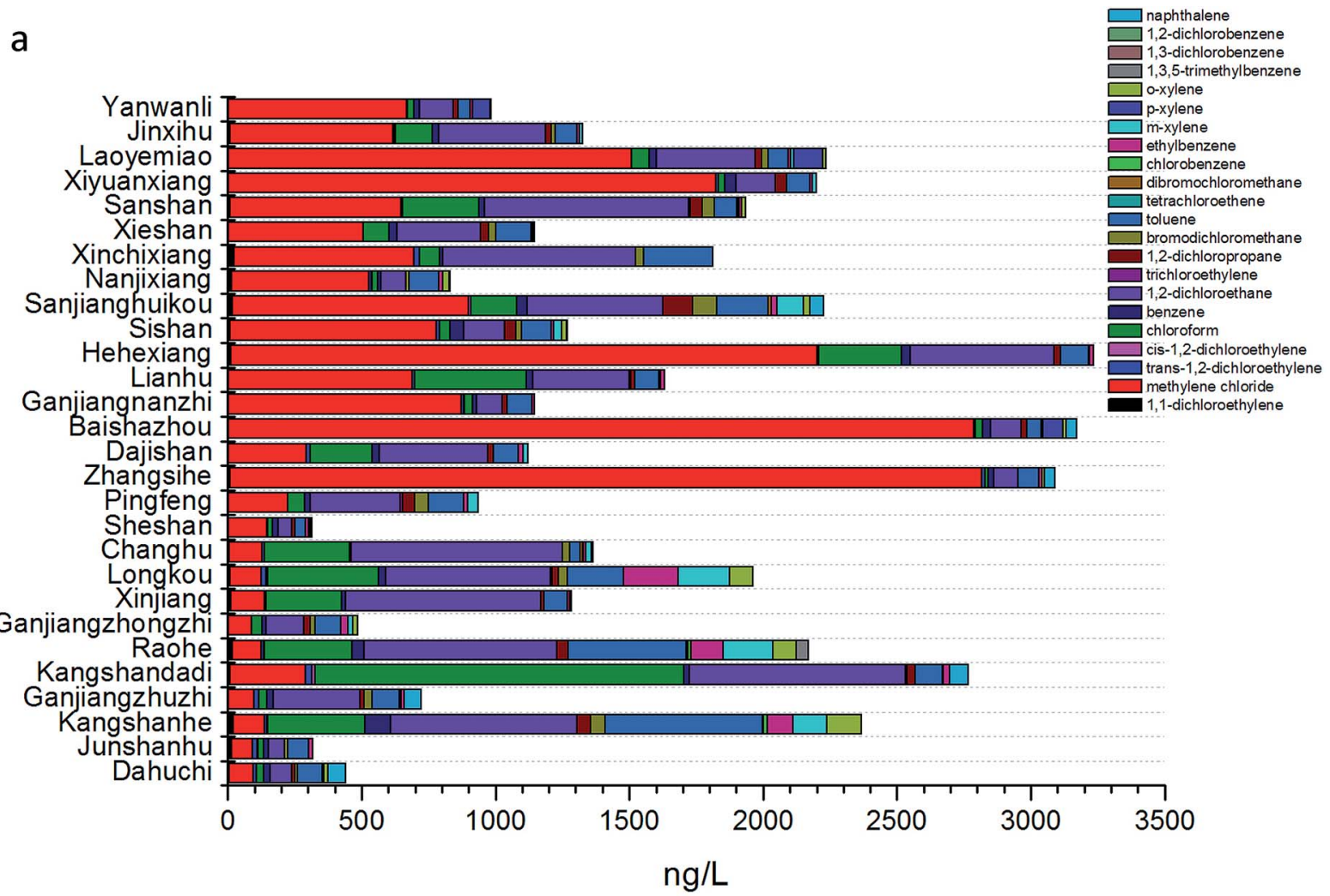

b

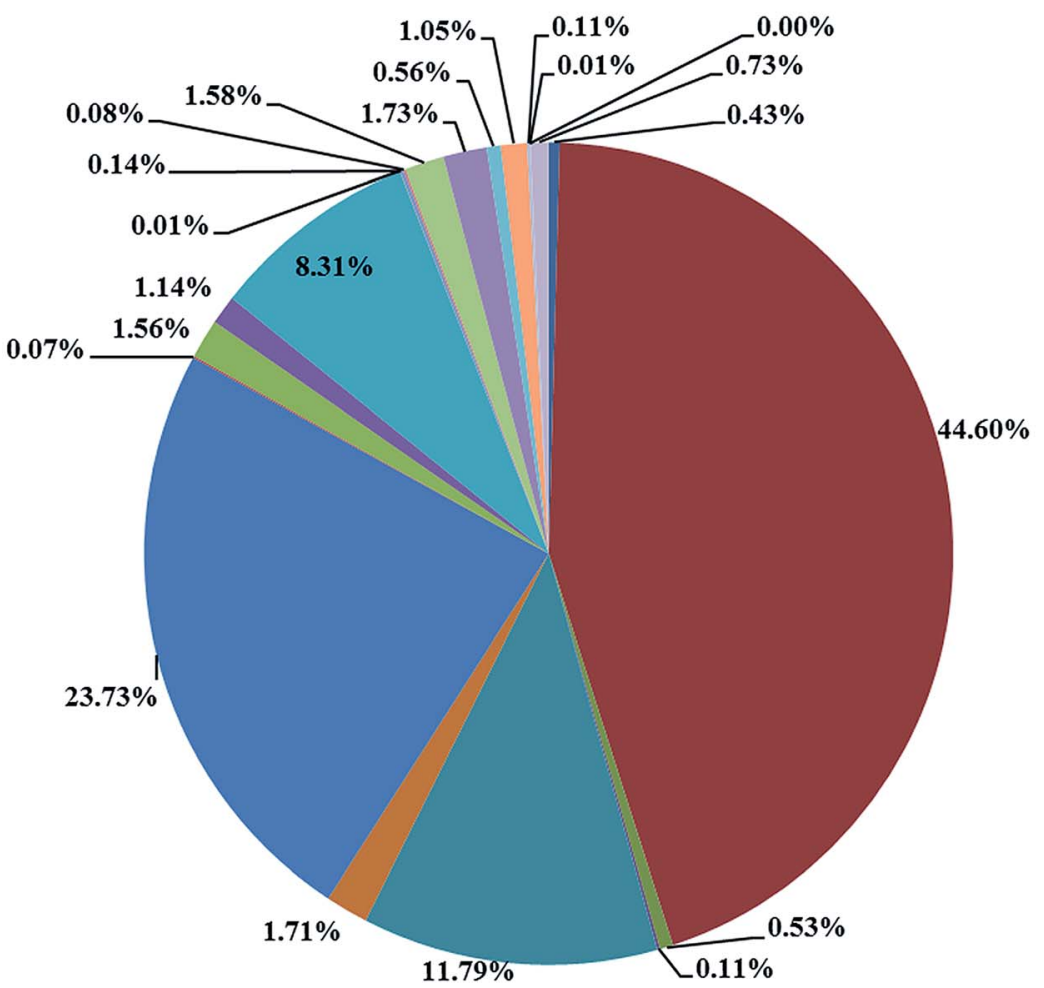

-1,1-dichloroethylene

- methylene chloride

- trans-1,2-dichloroethylene

u cis-1,2-dichloroethylene

n chloroform

benzene

-1,2-dichloroethane

घ trichloroethylene

1,2-dichloropropane

- bromodichloromethane

ntoluene

- tetrachloroethene

dibromochloromethane

chlorobenzene

匹 ethylbenzene

n m-xylene

$\square$-xylene

o-xylene

1,3,5-trimethylbenzene

1,3-dichlorobenzene

1,2-dichlorobenzene

naphthalene

Fig. 3 Distribution of VOC substances (a) at the sampling points and (b) in Poyang Lake.

than that in lakes, resulting in lower concentrations of VOCs in lakes than in rivers. It is inferred that the concentrations of VOCs in the atmosphere are higher than the concentrations in the water. Therefore, the atmosphere may be the source of VOCs in water. Based on this, VOC pollution in Poyang Lake was at a low level. 
Table 2 The distribution of VOC concentrations in lakes/rivers in the literature ${ }^{a}$

\begin{tabular}{|c|c|c|c|}
\hline Author & Lake/river & Number of VOCs detected & $\begin{array}{l}\text { Concentration } \\
\text { range }\left(\mu \mathrm{g} \mathrm{L}^{-1}\right)\end{array}$ \\
\hline Liu Y., et al. ${ }^{36}$ & Baitabao River & 14 & $\mathrm{ND} \sim 35.98$ \\
\hline & Huaihe River & & $\mathrm{ND} \sim 22.21$ \\
\hline & Yellow River & & $1.94-42.78$ \\
\hline & Haihe River & & $0.48-2.75$ \\
\hline Nystrom E. A. ${ }^{19}$ & Groundwater in Lake Champlain basin & 6 & $\mathrm{ND} \sim 11.8$ \\
\hline Han F. A., et al. ${ }^{37}$ & 21 water sampling points in Jiangsu, Zhejiang, and Shandong provinces & 19 & $\mathrm{ND} \sim 27.79$ \\
\hline Baehr A. L. \& Zapecza O. S. ${ }^{33}$ & Cranberry Lake and Lackawanna Lake & 6 & $\mathrm{ND} \sim 29.0$ \\
\hline Kostopoulou M. N., et al. ${ }^{34}$ & 4 rivers and 5 lakes in the region of northern Greece & 6 & $\mathrm{ND} \sim 40.0$ \\
\hline Fengmei Cao, et al. ${ }^{38}$ & Dongting Lake & 22 & $\mathrm{ND} \sim 1.06$ \\
\hline
\end{tabular}

\subsection{Risk}

Twenty-two types of VOCs were detected in Poyang Lake, and the health risks of ingestion and dermal intake (skin) were both evaluated. Some of the pollutant-related risk assessment parameters are not reported, of which the corresponding reference dose and carcinogenic slope factor are set to 0 .

According to the risk assessment formula in Section 2.5, the risk of VOCs in Poyang Lake was calculated. The results are shown in Table 3 . It can be concluded that the risk value of the human body via skin exposure (dermal risk) is much smaller than that caused by ingestion. It can be inferred that pollutants enter the body mainly through ingestion. This is similar to literature reports. ${ }^{39,40}$ According to the relevant definition of non-carcinogenic risk from the USEPA, when the risk index of a pollutant exceeds 1 , the pollutant is considered to be harmful to human health. The noncarcinogenic risk of 10 kinds of VOCs detected ranged from $6.29 \times 10^{-5}$ to $1.11 \times 10^{-1}$, which is much smaller than 1. As a result, the detected contaminants do not pose significant non-carcinogenic health risks to the human body, which is consistent with the results of $\mathrm{Chen}^{29}$ and
Cao. ${ }^{38}$ The acceptable carcinogenic risk index recommended by the USEPA is $1.0 \times 10^{-6}$, which means that lower values are acceptable. As we can see, the ingestion risk and total risk index of methylene chloride are $1.32 \times 10^{-6}$ and $1.33 \times$ $10^{-6}$, both higher than the standard limit. Therefore, it is believed that methylene chloride may cause cancer risk in Poyang Lake. The production, discharge and treatment of methylene chloride in Poyang Lake should receive greater focus. In Chen's study, ${ }^{29}$ crotonaldehyde in the Yangtze River basin, Huaihe River basin, Yellow River basin, Haihe River basin, and Liaohe River basin posed a low carcinogenic risk via drinking. However, some researchers have conducted health risk assessments of VOCs emitted during e-waste dismantling. ${ }^{41-44}$ The results showed that both cancer and non-cancer risks exist for workers due to exposure to on-site emitted VOCs at all e-waste dismantling workshops, which is different from our findings. This may be because the concentration of VOCs in indoor air is much higher than the concentration of VOCs in rivers and lakes. Therefore, source water may pose a potential carcinogenic risk because of the presence of methylene chloride if used for drinking.

Table 3 Carcinogenic risk and non-carcinogenic risk of volatile organic pollutants

\begin{tabular}{|c|c|c|c|c|c|c|}
\hline \multirow[b]{2}{*}{ Contaminants } & \multicolumn{3}{|c|}{ Carcinogenic risk } & \multicolumn{3}{|c|}{ Non-carcinogenic risk } \\
\hline & Ingestion risk & Dermal risk & Total risk & Ingestion risk & Dermal risk & Total risk \\
\hline 1,1-Dichloroethylene & & & & $1.28 \times 10^{-4}$ & $5.36 \times 10^{-7}$ & $1.28 \times 10^{-4}$ \\
\hline Methylene chloride & $1.32 \times 10^{-6}$ & $5.55 \times 10^{-9}$ & $1.33 \times 10^{-6}$ & $1.10 \times 10^{-1}$ & $4.62 \times 10^{-4}$ & $1.11 \times 10^{-1}$ \\
\hline cis-1,2-Dichloroethylene & & & & $8.33 \times 10^{-5}$ & $3.50 \times 10^{-7}$ & $8.37 \times 10^{-5}$ \\
\hline Chloroform & & & & $1.75 \times 10^{-2}$ & $7.33 \times 10^{-5}$ & $1.76 \times 10^{-2}$ \\
\hline Benzene & $7.60 \times 10^{-7}$ & $3.19 \times 10^{-9}$ & $7.63 \times 10^{-7}$ & $5.06 \times 10^{-2}$ & $2.13 \times 10^{-4}$ & $5.09 \times 10^{-2}$ \\
\hline Bromodichloromethane & $5.76 \times 10^{-7}$ & $2.42 \times 10^{-9}$ & $5.79 \times 10^{-7}$ & $5.65 \times 10^{-2}$ & $2.37 \times 10^{-4}$ & $5.68 \times 10^{-2}$ \\
\hline Toluene & & & & $1.27 \times 10^{-2}$ & $5.33 \times 10^{-5}$ & $1.28 \times 10^{-2}$ \\
\hline Dibromochloromethane & $8.24 \times 10^{-8}$ & $3.46 \times 10^{-10}$ & $8.27 \times 10^{-8}$ & $1.03 \times 10^{-4}$ & $4.32 \times 10^{-7}$ & $1.03 \times 10^{-4}$ \\
\hline Chlorobenzene & & & & $6.26 \times 10^{-5}$ & $2.63 \times 10^{-7}$ & $6.29 \times 10^{-5}$ \\
\hline Ethylbenzene & & & & $1.06 \times 10^{-4}$ & $4.45 \times 10^{-7}$ & $1.07 \times 10^{-4}$ \\
\hline
\end{tabular}




\section{Conclusion}

Twenty-two VOC pollutants were detected in surface waters of Poyang Lake. Methylene chloride, 1,2-dichloroethane and chloroform had both maximum detected concentration values and $100 \%$ FODs. VOCs are widely distributed in Poyang Lake, but the concentrations of detected VOCs did not exceed the limits of national standards. The number of VOCs detected in Poyang Lake was obviously higher than those in other lakes and rivers. The concentrations of VOCs detected in lakes were smaller than those in rivers. This is due to the possible transfer of VOCs from the atmosphere to the water, and turbulence may be the main cause of the difference. The health risks of ingestion and dermal exposure in Poyang Lake were both evaluated. No contaminants have a significant non-carcinogenic health risk to humans, but methylene chloride may cause cancer risk to individuals. Since methylene chloride is mainly used in the fields of film production and medicine in China, it is very important to control the pollution from the film and pharmaceutical industry in Poyang Lake basin. This investigation is being continued to provide more information on VOC concentrations in surface waters of Poyang Lake.

\section{Conflicts of interest}

There are no conflicts to declare.

\section{Acknowledgements}

This work was financially supported by the Ministry of Science and Technology of China (Grant No. 2015FY110900).

\section{References}

1 Z. Zhang, J. Chen, Y. Gao, Z. Ao, G. Li, T. An and Y. Li, J. Cleaner Prod., 2018, 185, 266-274.

2 M. Jiang, L. Zou, X. Q. Li, F. Che, G. H. Zhao, G. Li and G. N. Zhang, Huanjing Kexue, 2015b, 09, 3522-3532.

3 M. S. Kamal, S. A. Razzak and M. M. Hossain, Atmos. Environ., 2016, 140, 117-134.

$4 \mathrm{~W}$. Wei, Study on current and future anthropogenic emissions of volatile organic compounds in China, $\mathrm{PhD}$ thesis, Tsinghua University, Beijing, China, 2009.

5 A. L. Dos Santos Fonseca, C. C. Marinho and F. De Assis Esteves, Wetlands, 2017, 37(4), 763-771.

6 P. Fellin and R. Otson, Atmos. Environ., 1994, 28(22), 35813586.

7 J. S. Han, M. D. Lee, Y. J. Lim, S. U. Lee, Y. M. Kim, B. J. Kong and Y. D. Hong, Journal of Korean Society for Atmospheric Environment, 2006, 22(5), 574-589.

8 J. B. Jiang, W. Jin, L. L. Yang, Y. Feng, Q. Chang, Y. Q. Li and J. B. Zhou, Environ. Monit. China, 2015a, 31(1), 79-84.

9 J. Chen, Y. Huang, G. Li, T. An, Y. Hu and Y. Li, J. Hazard. Mater., 2016a, 302, 395-403.

10 C. B. Zhang, W. L. Liu, W. J. Han, M. Guan, J. Wang, S. Y. Liu and J. Chang, Wetlands, 2017, 37(1), 109-122.
11 T. Yue, X. Yue, F. Chai, J. Hu, Y. Lai, L. He and R. Zhu, Atmos. Environ., 2017, 151, 62-69.

12 G. Gałęzowska, M. Chraniuk and L. Wolska, Trends Anal. Chem., 2016, 77, 14-22.

13 Y. Gong, Y. Wei, J. Cheng, T. Jiang, L. Chen and B. Xu, Sci. Total Environ., 2017, 574, 1432-1438.

14 Y. M. Yang, J. S. Cui, L. Tong, X. S. Zhou and H. Niu, Res. Environ. Sci., 2017, 30(3), 368-379.

15 Z. Ni, J. Liu, M. Song, X. Wang, L. Ren and X. Kong, J. Environ. Sci., 2015, 29, 34-44.

16 H. Guo, Q. Hu and T. Jiang, J. Hydrol., 2008, 355(1), 106-122. 17 Z. He, G. Li, J. Chen, Y. Huang, T. An and C. Zhang, Environ. Int., 2015, 77, 85-94.

18 W. M. Kuang, M. Zhang and J. M. Zhang, J. Lake Sci., 2016, 28(6), 1293-1305.

19 E. A. Nystrom, Groundwater quality in the Lake Champlain Basin, US Geological Survey, New York, (no. 2011-1180), 2011.

20 K. Krishnan, J. Paterson and D. T. Williams, Regul. Toxicol. Pharmacol., 1997, 26(2), 179-187.

21 R. Sadiq and M. J. Rodriguez, Sci. Total Environ., 2004, 321(1), 21-46.

22 V. T. Covello and M. W. Merkhoher, Risk assessment methods: approaches for assessing health and environmental risks, Springer Science \& Business Media, 2013.

23 US Environmental Protection Agency, Guidelines for exposure assessment. Fed. Reg., 1992, vol. 57, no. 104, pp. 22888-22938.

24 X. L. Duan, N. Huang, B. B. Wang, X. G. Zhao, J. Nie, Y. Qian and J. L. Zhang, J. Environ. Health, 2012, 29(2), 99-104.

25 G. P. Li, L. H. Xu, G. F. Huang, Y. F. Lv and L. W. Huang, J. Zhejiang Univ. Technol., 2014, 42(5), 528-532.

26 D. D. Zhang, Y. Xie and X. Liu, Res. Environ. Sci., 2012, 25(12), 1398-1403.

27 S. Q. Zhang, L. S. Fu, C. Liu and Q. H. Lv, Chin. J. Environ. Eng., 2004, 5(1), 47-50.

28 Z. Y. Zhu, M. Q. Chen, J. H. Cao, H. S. Cai, H. S. Huang, B. Liu and Z. J. Luo, Reformation \& Strategy, 2009, 25(5), 132-135.

29 X. Chen, Q. Luo, D. Wang, J. Gao, Z. Wei, Z. Wang and A. Mazumder, Environ. Pollut., 2015, 206, 64-72.

30 C. A. Snyder, Experimental benzene toxicity, in Benzene carcinogenicity, CRC Press, 2017, pp. 29-38.

31 W. Li and X. Y. Li, Hebei Huagong, 1997, 4, 36-37.

32 R. Q. Mao and Y. X. Wen, Mod. Chem. Ind., 2005, 25(10), 6265.

33 A. L. Baehr and O. S. Zapecza, Water-Resour. Invest. Rep., 1998, 98, 4264.

34 M. N. Kostopoulou, S. K. Golfinopoulos, A. D. Nikolaou, N. K. Xilourgidis and T. D. Lekkas, Chemosphere, 2000, 40(5), 527-532.

35 A. D. Nikolaou, S. K. Golfinopoulos, M. N. Kostopoulou, G. A. Kolokythas and T. D. Lekkas, Water Res., 2002, 36(11), 2883-2890.

36 Y. Liu, L. Han, Y. H. Song and A. J. Gong, Acta Sci. Circumstantiae, 2013, 33(11), 3038-3046.

37 F. A. Han, J. Chen and Z. F. Jiang, J. Environ. Health, 2011, 28(10), 890-894. 
38 F. Cao, P. Qin, S. Lu, Q. He, F. Wu, H. Sun, L. Wang and L. Li, Ecotoxicol. Environ. Saf., 2018, 165, 645-653.

39 Z. W. Tang, J. L. Chen, H. Y. Zhang and X. Y. Fan, Journal of Hydraulic Engineering, 2009, 9, 1064-1069.

40 X. Ren, G. Zeng, L. Tang, J. Wang, J. Wan, Y. Liu, J. Yu, H. Yi, S. Ye and R. Deng, Sci. Total Environ., 2018, 610, 1154-1163.

41 G. Li, Z. Zhang, H. Sun, J. Chen, T. An and B. Li, J. Hazard. Mater., 2013, 250, 147-154.
42 T. An, Y. Huang, G. Li, Z. He, J. Chen and C. Zhang, Environ. Int., 2014, 73, 186-194.

43 J. Chen, D. Zhang, G. Li, T. An and J. Fu, Chem. Eng. J., 2016b, 301, 299-305.

44 R. Liu, J. Chen, G. Li and T. An, Chem. Eng. J., 2017, 318, 5763. 